\title{
Comparison of greenhouse gas emissions from different vehicles covering the entire life cycle
}

\author{
J. Perez ${ }^{1}$, J. Lumbreras ${ }^{1}$, J. M. López ${ }^{2}$, J. A. Garcia ${ }^{2}$, \\ M. Vedrenne ${ }^{1}$, J. M. de Andrés \& D. Paz \\ ${ }^{I}$ Department of Chemical \& Environmental Engineering, UPM, Spain \\ ${ }^{2}$ University Institute for Automobile Research (INSIA), UPM, Spain
}

\begin{abstract}
The aim of this paper is to compare the greenhouse gas (GHG) emissions from different types of vehicles, including electric and hybrid, during their entire life cycle. To estimate these emissions, a tool developed by the Technical University of Madrid (UPM), GlobalTRANS, was used. This tool integrates not only Tankto-Wheel emissions (exhaust), but also Well-to-Tank, vehicle manufacturing and disposal emissions.

In this study a typical Battery Electric Vehicle (BEV) was compared with traditional internal combustion vehicles, such as gasoline, diesel or LPG cars as well as with hybrid vehicles (electric-gasoline) for the Spanish case.

Finally, a sensitivity analysis was done to evaluate the influence of the BEV's electric consumption on its GHG emissions. For this purpose, emissions were estimated using GlobalTRANS modifying the electric consumption of the vehicle within the range of $100-250 \mathrm{Wh} / \mathrm{km}$, in accordance with $\mathrm{BEV}$ catalogue vehicles available in the Spanish market.
\end{abstract}

Keywords: greenhouse gas emissions, electric vehicles, life cycle, road transport, hybrid vehicles.

\section{Introduction}

The transport sector, either passenger or freight transport, is an activity of great importance under social and economic point of view. However, it is also the main source of atmospheric pollution and greenhouse gas (GHG) emissions $[1,2]$. This issue has deep consequences on human health and ecosystems, 
associated invariably with the worsening of air quality [3] and contributing sensitively to climate change.

Within this sector, road transport accounts for a high percentage of total anthropogenic emissions. For instance, in Spain, it constitutes the $23 \%$ of the total GHG emissions [4].

Strategic planning in transport must, therefore, take into consideration the aforementioned environmental impacts and, aiming to its minimization, the adoption of policies and measures that abate emissions and energy consumption.

In order to estimate the effect of these measures, it is crucial to consider the complete life cycle emissions and not only those produced during the fuel combustion phase [5].

Nowadays, the strong irruption of new technologies such as the hybrid vehicle or the electric vehicle makes necessary a strict analysis of the GHG emissions throughout their entire life cycle, compared to traditional technologies available in the market. Among these new technologies, the expansion of the electric vehicle (Battery Electric Vehicles, BEV) stresses the need of carrying out an exhaustive analysis of the different available types as a function of their consumption per travelled kilometer.

\section{Methodology}

In order to evaluate the emission of GHG throughout the vehicle's life cycle, the Technical University of Madrid (UPM) developed a computer application, GlobalTRANS, as an extension of the EmiTRANS tool [6], which allowed the determination of emissions associated only to vehicle fuel consumption. This new application has been developed as part of the project 072/P08/3.13.2 called "Development of a tool for the evaluation of the global life cycle emissions for road transport" under the 2008-2011 Spanish National R\&D plan.

Therefore, GlobalTRANS allows the characterization of the GHG emissions for a vehicle or a vehicle fleet considering their manufacture and use (energy consumption, maintenance and waste management). Moreover, it facilitates the decision-making process when selecting alternatives to reduce GHG emissions from the transport sector.

\subsection{Software tool development}

The computer tool is structured in three modules (modules 1-3) that consider the different life cycle stages of a vehicle along with an additional module (module 0 ) treating the emissions derived from power generation:

- Module 0: emissions from electricity production

- Module 1: emissions from vehicle manufacturing and disposal

- Module 2: emissions from Well-to-Tank (WtT)

- Module 3: emissions from Tank-to-Wheel (TtW)

Emissions are calculated for each vehicle type or fleet through a series of calculation algorithms that are fed with initial data concerning activity variables (number of vehicles, annual mileage, mean velocities, etc.). These algorithms 
include specific emission factors and consumptions that are necessary for the entire life cycle analysis of vehicles used in the road transport sector (as detailed in EUCAR, JCR and CONCAWE [7], Choudhury [8] and General Motors [9]).

Using these activity data, the tool evaluates energy consumption and GHG emissions. By default, the application includes specific activity data for Spain although it is easily modifiable to include information describing any spatial or temporal domain. The minimum activity data for every module are listed in Table 1.

Table 1: Activity data used for the calculation of energy consumption and GHG emissions in each module.

\begin{tabular}{|c|c|}
\hline Module & Activity data \\
\hline 0 & $\begin{array}{l}\text { Energy efficiency for each technology } \\
\text { Power generation mix } \\
\text { Specific GHG emissions }\end{array}$ \\
\hline 1 & $\begin{array}{c}\text { Vehicle weight } \\
\text { Total travelled mileage during vehicle's lifetime } \\
\text { Electric and thermal energy share in the manufacturing processes } \\
\text { Material composition of vehicles } \\
\text { Material composition of vehicles used in the disposal of out-of-use } \\
\text { vehicles }\end{array}$ \\
\hline 2 & $\begin{array}{c}\text { Origin of the consumed fuels (route characterization) } \\
\text { Biofuel consumption } \\
\text { Energy consumption during the vehicle use phase }\end{array}$ \\
\hline 3 & $\begin{array}{c}\text { Vehicle fleet } \\
\text { Total travelled mileage during vehicle's lifetime } \\
\text { Mean fleet speeds according to driving patterns (highway, rural, } \\
\text { urban) } \\
\text { Trip percentage completed under every driving pattern } \\
\text { Fuel specifications } \\
\end{array}$ \\
\hline
\end{tabular}

When default data for Spain are used, input categories are reduced to the number of vehicles for every type. The rest of categories have been already incorporated into the model's structure and estimated through the use of characteristic information, available for the Spanish case [4].

\subsubsection{Module 0 - Power production}

This module estimates emissions associated to power production, distinguishing the use of electricity at the manufacturing and assembly processes, and as energy source for the electric vehicles (EV). For this case, the energy transferred to the vehicle has been excluded (as done in EUCAR, JCR and CONCAWE [7]).

The information concerning power generation embedded in the tool corresponds to the Spanish energy mix, as reported by MITYC [10]. The GHG emissions imputable to the production and consumption of electricity was evaluated according to Lumbreras et al. [11]. 
Data regarding the construction and decommissioning of power plants, as well as the associated waste treatments are not included in this tool due to their great variability and lack of comparability [12].

\subsubsection{Module 1 - Vehicle manufacturing and disposal}

This module calculates emissions from the respective life cycles of the vehicle materials. The considered phases are as follows:

1. Raw material extraction and manufacturing: incorporating data from GaBi-4 tool [13] and IKP [14].

2. Vehicle manufacture and assembly: data from GaBi-4 tool [13] and IKP [14].

3. Vehicle maintenance: an equation that relates energy consumption, lifetime and vehicle weight is used, as published in Sullivan et al. [15].

4. Waste management system (e.g. disposal, recycling, etc.): a relationship between energy consumption, lifetime and vehicle weight is used, according to Sullivan et al. [15].

Using these references, two coefficients for each vehicle type were calculated using Copert 4 vehicle classification [16]. These coefficients comprise energy consumption and GHG emissions.

\subsubsection{Module 2 - Well-to-Tank (WtT)}

This module estimates emissions from the production of those energy sources used in the considered vehicles. It includes extraction of raw materials, along with their processing, further transformations and transportation. These are applied to either raw material, intermediate or final products.

The energy sources considered are: diesel, gasoline, natural gas, liquefied petroleum gas, biodiesel, bioethanol and electricity. However, it also calculates emissions from additives production such as ETBE [7]. Information regarding the relative route of biofuels for Spain was provided by CIEMAT [17].

In order to compute the GHG emissions for every stage and energy source type, it was necessary to know the energy consumption for each vehicle (or fleet). To this respect, the algorithms contained in Copert 4 were implemented. As for $\mathrm{BEV}$, it was estimated as a function of the consumption factor in $\mathrm{Wh} / \mathrm{km}$ and the total travelled distance during lifetime.

\subsubsection{Module 3 - Tank-to-Wheel (TtW)}

The third module was developed to provide exhaust GHG emissions for a userdefined vehicle or fleet. Copert 4 [16] algorithms have also been used to provide a reasonable estimation.

As mentioned before, it is also necessary to include information on the percentages of total travelled distance completed under every driving mode (highway, rural, urban), the average speed under each mode and the travelled mileage during lifetime. Figure 1 depicts the general structure of GlobalTRANS and its four modules. 


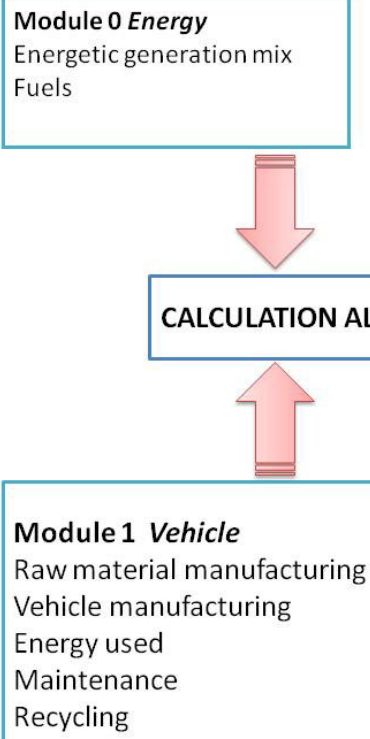

\section{Module 2 Well-To-Tank}

Extraction

Refining-manufacturing

Transport

Distribution and dispensing

\section{$\mathrm{CO}_{2}$ eq.} emissions

\section{Module 2 Exhaust emissions}

Population

Mileage

Speed

Fuel

Fleet

Driving mode (rural, urban,...)

Figure 1: GlobalTRANS structure.

\subsection{Application to the case study (Spain)}

GlobalTRANS was applied to compare GHG emissions produced during the entire life cycle of several passenger cars, including a BEV. Additionally, a comparison between different BEV consumptions was done.

The chosen vehicles for the first comparison are included in the categories defined by Copert 4 [16] and listed in Table 2.

Table 2: $\quad$ Compared vehicles.

\begin{tabular}{|c|}
\hline Vehicle type \\
\hline Gasoline (GSL) $<1.4$ litres (l) \\
\hline GSL $1.4-2.01$ \\
\hline GSL $>2.01$ \\
\hline Diesel (D) $<2.01$ \\
\hline D $>2.01$ \\
\hline Liquefied Petroleum Gases (LPG) \\
\hline Hybrid gasoline (HYB) $<1.41$ \\
\hline HYB $1.4-2.01$ \\
\hline HYB $>2.01$ \\
\hline Battery Electric Vehicle $(\mathrm{BEV}), 135 \mathrm{Wh} / \mathrm{km}$ \\
\hline
\end{tabular}


In the case of the BEV, a consumption of $135 \mathrm{Wh} / \mathrm{km}$ was used as specific value for a commercial model available in the Spanish market according to IDAE [18].

Afterwards, a comparison between the emissions of the complete life cycle was made for different $\mathrm{BEV}$, only modifying power consumption from 100 to $250 \mathrm{Wh} / \mathrm{km}$ (specifically 100, 150, 200 and 250). According to IDAE [18], available BEV in the Spanish market exhibit consumptions between 90 and 175 $\mathrm{Wh} / \mathrm{km}$.

In order to have intercomparable datasets, the rest of parameters were kept constant (i.e. total mileage, driving modes distribution and average speed). Moreover, a series of typical driving conditions were used for every vehicle as presented in Table 3. These data were derived from MARM [4] for the Spanish case in 2009 and correspond to average values.

Table 3: $\quad$ Typical driving conditions.

\begin{tabular}{|c|c|c|}
\hline \multicolumn{2}{|c|}{ Parameter } & Value \\
\hline Entire life cycle mileage (km) & 200.000 \\
\hline Distribution & Urban & 32 \\
\cline { 2 - 3 } by driving & Rural & 19 \\
\cline { 2 - 3 } mode (\%) & Highway & 49 \\
\hline \multirow{2}{*}{ Average } & Urban & 25 \\
\cline { 2 - 3 } Speed $(\mathrm{km} / \mathrm{h})$ & Rural & 65 \\
\cline { 2 - 3 } & Highway & 105 \\
\hline
\end{tabular}

\section{Results and discussion}

Figure 2 shows total GHG emissions comparison for the selected vehicles during the entire life cycle (in terms of $\mathrm{CO}_{2}$ equivalent) while Figure 3 depicts the same information in relative terms, assigning a 100 value to the $\mathrm{BEV}$ emissions in

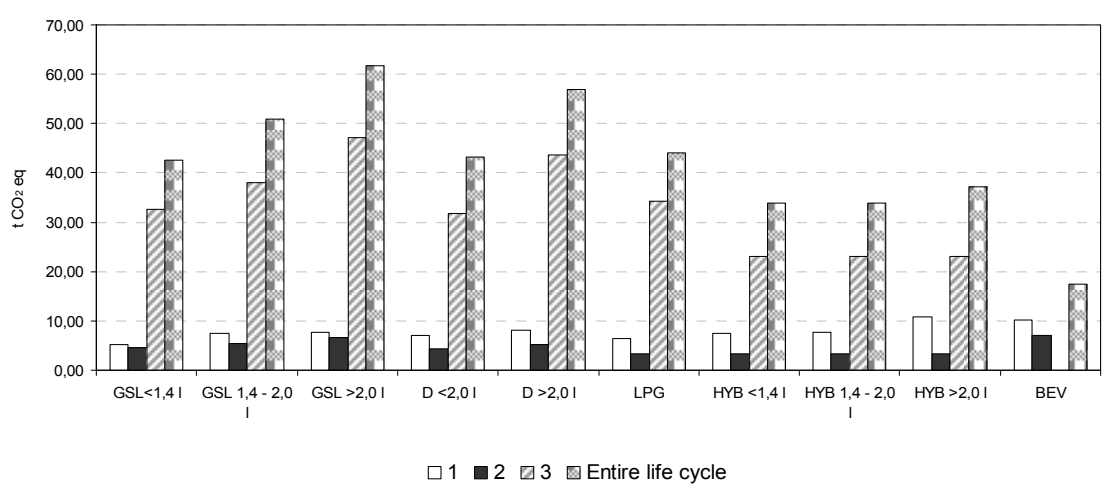

Figure 2: GHG emissions for the different vehicle types compared in their entire life cycle. 


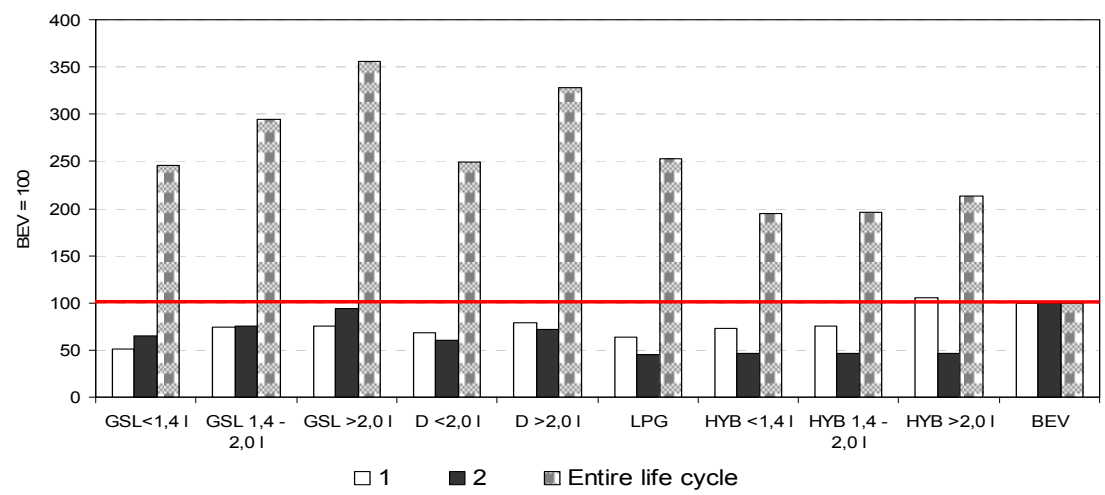

Figure 3: Comparison between the emissions of the BEV with the rest of the analyzed vehicles.

each of its life cycle stages. Each of these stages was numbered from one to three according to their respective GlobalTRANS module:

- 1: Vehicle manufacturing and disposal

- 2: Well-to-tank

- 3: Tank-to-wheel

It can be observed that the BEV has sensitively lower GHG emissions during its life cycle compared to the rest of vehicles. Its emission levels are always less than half of their hybrid equivalents (17.3 $\mathrm{CO}_{2 \text { eq }}$ tons against 33-37 tons for gasoline hybrid). Conventional passenger cars present emissions which are from $145 \%$ to $256 \%$ higher than the BEV (42.5-61.7 vs. 17.3 tons). The highest emission (61.7) corresponds to high cylinder capacity vehicles $(>2.01)$. Diesel vehicles on its behalf, exhibit emissions $149 \%$ higher for engine cylinder capacity below 2.01 (43.2 tons) and 228\% for those with higher cylinder capacities (56.9 tons). LPG-fuelled passenger cars might produce emissions up to 43.9 tons for their entire life cycle which are a $153 \%$ above those of the BEV.

Figure 4 represents emissions from each life cycle stage separately. It shows that emissions are mainly produced during stage 3 (Tank-to-Wheel) except for the $\mathrm{BEV}$, without any emissions for this phase. As for the internal combustion vehicles, this stage represents more than $74 \%$ of total emissions, being high cylinder capacities passenger cars those presenting the highest absolute amount (Figure 3). The reason is the highest fuel consumption per traveled kilometer.

BEV exhibits GHG emissions only for stages 1 (vehicle manufacturing and disposal) and 2 (Well-to-Tank), apportioning $59 \%$ and $41 \%$ of them, respectively. Conversely, for stage 2 , the BEV presents the highest emission values. In stage 1, hybrid and electric vehicles show higher emissions than traditional passenger cars and their contribution to the total emissions is higher: $22-29 \%$ for hybrid cars and $51 \%$ for the BEV. These emissions are related to maintenance operations and end-of-use vehicle disposal. In both cases, the BEV presents the highest emissions among the analyzed options. For maintenance operations, BEV emissions are $17-33 \%$ higher than those produced by fossil-fuel 
vehicles and 7-23\% above the hybrid vehicle. In the case of end-of-use vehicle disposal operations, gasoline passenger cars yielded $33-55 \%$ less the BEV emissions, followed by LPG-fuelled vehicles (43\% lower), diesel vehicles (28$38 \%$ lower) and hybrid cars (12-39\% less).

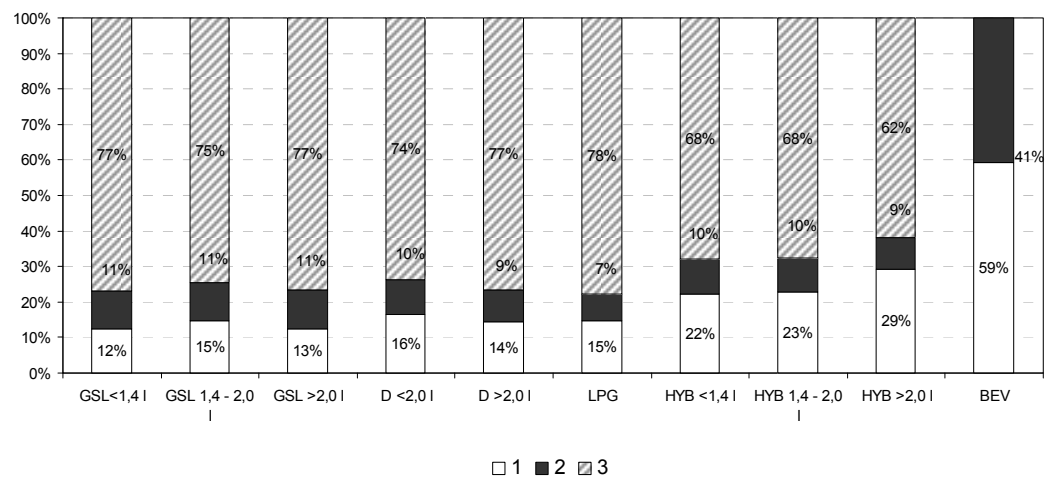

Figure 4: Contribution of each of the life cycle stages to the total life cycle emissions.

For stage 2, the BEV presents the highest emissions as a consequence of its power consumption, producing emission values $118 \%$ higher if compared to hybrid cars, $6-54 \%$ higher if compared to gasoline vehicles (depending on cylinder capacity) and 38-64\% higher if compared to diesel vehicles (depending also on cylinder capacity).

To determine the influence of the BEV power consumption on total life cycle emissions, these have been changed from 100 to $250 \mathrm{Wh} / \mathrm{km}$. Consequently, Figure 5 presents GHG emissions for different consumption values in absolute terms and Figure 6 in relative terms, assigning a 100 value to the less consumption vehicle $(100 \mathrm{Wh} / \mathrm{km})$ in each of its life cycle stages.

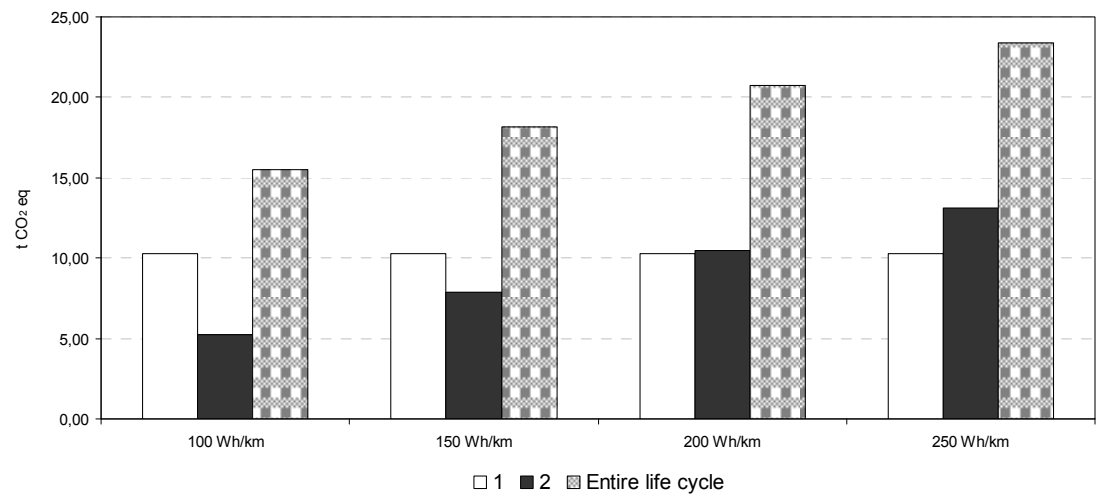

Figure 5: $\quad$ GHG emissions for different BEVs as a function of their electric consumption per travelled kilometer. 
Figure 5 shows that the emissions in stage 1 remained constant as a consequence of varying only the specific consumption of the BEV without modifying the rest of the vehicle parameters (weight, material composition, etc.). Due to the fact that the BEV does not present any emissions for stage 3 (Tank-toWheel), the only variation was evident for stage 2 (Well-to-Tank) where emissions increased proportionally to electric consumptions (Figure 6).

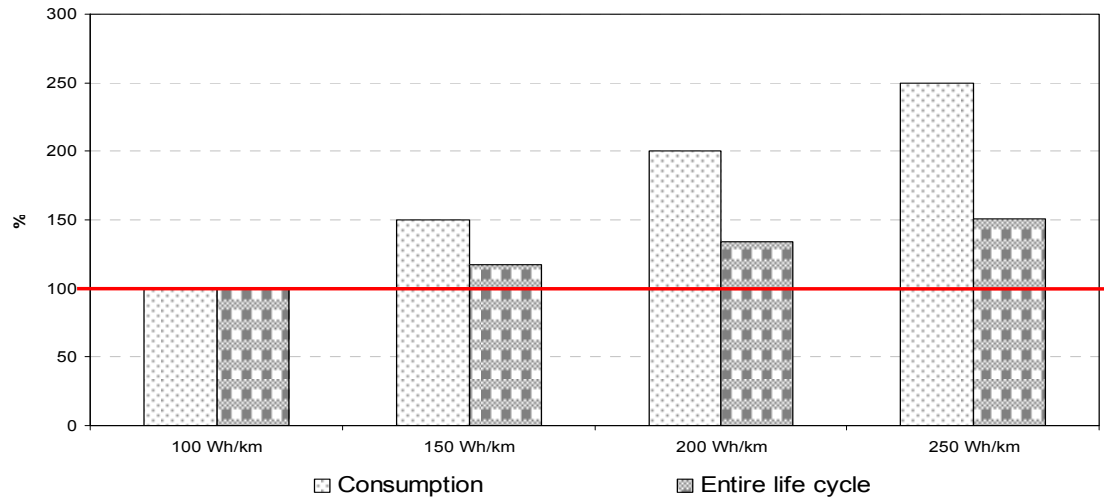

Figure 6: Variation of the emissions of the BEV during its entire life cycle as a function of the electric consumption per travelled $\mathrm{km}$.

A $50 \%$ increase of BEV consumption causes a $17 \%$ GHG increment. However, the contribution of this stage to total emissions increases as stated in Figure 7.

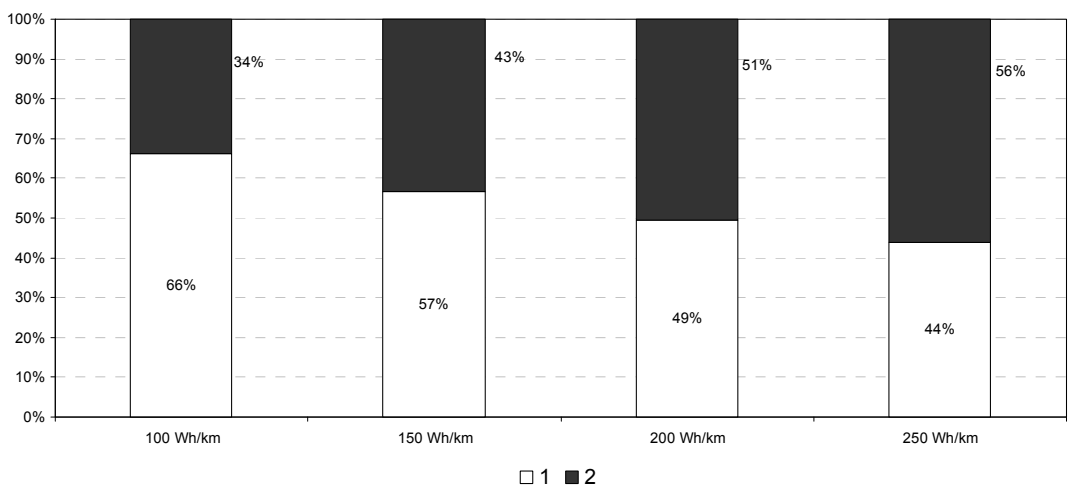

Figure 7: Contribution of each of the life cycle stages to the emissions of the entire BEV life cycle. 


\section{Conclusions}

GlobalTRANS quantifies GHG emissions from the entire life cycle of a vehicle or a vehicle fleet for road transport. This tool allows policy makers and company managers to compare different alternatives for a vehicle in terms of their GHG emissions.

An average $\mathrm{BEV}$ is able to reduce from $59 \%$ to $72 \%$ of $\mathrm{GHG}$ emissions in the entire life cycle with respect to those generated by traditionally-fuelled cars (gasoline, diesel, LPG). Concerning hybrid gasoline vehicles, emissions are reduced a $50 \%$.

For internal combustion vehicles, stage 3 (Tank-to-Wheel) accounts for the majority of the GHG emissions (74-78\%). On the contrary, the BEV presents its major emission share at stage 1 (vehicle manufacturing and disposal) and 2 (Well-to-Tank), with an ever increasing contribution of the second stage along with electric consumption. In these stages, the BEV exhibits higher emissions than the rest of vehicles, even doubling them in some cases (especially at stage 2 ). Yet, as it does not present any emissions in stage 3, the global emissions for this vehicle are way lower.

BEV emissions from maintenance and end-of-use vehicle management (both within stage 1) are higher than for the rest of the analyzed vehicles. According to the obtained results, despite the fact that BEVs might exhibit consumptions above $200 \mathrm{Wh} / \mathrm{km}$, it would still present lower GHG emissions, even 50\% lower than those generated by a traditional gasoline or diesel car.

The presented results consider the electric generation mix for Spain in 2009 (MITYC [10]), which determines the indirect GHG emissions (due to electric consumption and not exhaust) for the BEV. The expansion of renewable energies in Spain strongly hints that any specific emissions from the electric sector might decrease, making the BEV even more GHG-emission friendly than the rest of technologies. According to MITYC [10], in 2009 the GHG emissions derived from power generation in Spain ascended to $0.36 \mathrm{ktCO}_{2} / \mathrm{GWh}$, in terms of final consumption, with a contribution of $26 \%$ of renewable sources. For 2010 the contribution of renewable energies rose up to $33.6 \%$ with a specific emission of $\mathrm{GHG}$ of $0.28 \mathrm{ktCO}_{2} / \mathrm{GWh}$ [19], forecasting an even more encouraging scenario for the BEV.

\section{References}

[1] European Environment Agency, Annual European Union Greenhouse Gas Inventory 1990-2009 and Inventory report 2011, Technical Report No. 2/2011.

[2] European Environment Agency, NEC Directive status report 2010, Technical Report No. 2/2011.

[3] Kampa, M., Castanas. E., Human health effects of air pollution. Environmental Pollution 151, 2008, Pages 362-368, 2008.

[4] Ministerio de Medio Ambiente y Medio Rural y Marino, MARM, Inventario Nacional de Emisiones a la Atmósfera 1990-2009, 2011. 
[5] Chatterton T.J., Coulter, A., Musselwhite, C., Lyons, G., Clegg, S., Understanding how transport choices are affected by the environment and health: Views expressed in a study on the use of carbon calculators. Public Health 123 (2009) e45-e49, 2008.

[6] Lumbreras, J., Rodriguez, M.E., López, J.M., Guijarro, A., Villimar, R., Pérez, J., Herramienta integral para el cálculo de emisiones atmosféricas del transporte por carretera, Escuela Técnica Superior de Ingenieros Industriales, Universidad Politécnica de Madrid, 2008.

[7] EUCAR/JRC/CONCAWE, Well-to-Wheels analysis of future automotive and powertrains in the European context, Version 3, 2008.

[8] Choudhury, R., General Motors, Well-To-Wheel Analysis of energy use and greenhouse gas emissions of advanced fuel/vehicle systems- a European study. L-B-Systemtechnik GmBH, 2002.

[9] General Motors Corporation, Argonne National, BP, Exxonmobil, Shell, Well-to-Tank Energy Use and Greenhouse Gas Emissions of Advanced Fuel/Vehicle Systems: North American Analysis, Final Report, 2001.

[10] Ministerio de Industria, Turismo y Comercio, El Libro de la Energía en España 2009, 2010.

[11] Lumbreras, J., Borge, R., de Andres, J.M., Rodriguez, M.E., A model to calculate consistent atmospheric emission projections. Application to Spain. Atmospheric Environment, 42/21, 5251-5266, 2008.

[12] Lenzen, M., Life cycle energy and greenhouse gas emissions of nuclear energy: A review, Energy Conversion and Management 49, 2178-2199, 2008.

[13] GaBi 4 software [http://www.gabi-software.com/]

[14] IKP-Institute for Polymer Testing and Polymer Science of the University of Stuttgart and PE Europe $\mathrm{GmbH}$, IKP-Institute for Polymer Testing and Polymer Science of the University of Stuttgart and PE Europe GmbH, 2003.

[15] Sullivan, J.L., Williams, R. L., Yester, S., Cobas, E., Chubbs, S.T., Hentges, S.G., Pomper, S.D., Life Cycle Inventory of a Generic U.S. Family Sedan, Overview of Results USCAR AMP Project, DOI: 10.4271/982160, 1998.

[16] Gkatzoflias, D., Kouridis, C., Ntziachristos, L., Samaras, Z., COPERT 4, Computer Programme to Calculate Emissions from Road Transport. Aristotle University Thessaloniki/European Environment Agency, 2007. [http://lat.eng.auth.gr/copert/]

[17] CIEMAT, Análisis de ciclo de vida de combustibles alternativos para el transporte, 2008.

[18] IDAE, Catálogo MOVELE de vehículos, http://www.movele.es/ index.php/mod.coches/mem.listado/relmenu.15, 2012.

[19] Ministerio de Industria, Turismo y Comercio, El Libro de la Energía en España 2010, 2011. 